\title{
Craniofacial conodysplasia
}

INSERM

\section{Source}

INSERM. (1999). Orphanet: an online rare disease and orphan drug data base.

Craniofacial conodysplasia. ORPHA:85168

Craniofacial conodysplasia is characterised by craniofacial dysplasia, cone-shaped physes of the hands and feet, and neurological manifestations resembling cerebral palsy. It has been described in one family. The syndrome appeared to be transmitted as a dominant trait. 